\title{
Immunohistochemical Evaluation of mTOR and Beclin-1 Protein Expression in Human Breast Cancer and Adjacent Normal Tissues, A Study in Malaysian Patients
}

\author{
Ahmad Faisal Mutee ${ }^{1}$, Gurjeet Kaur ${ }^{1}$, Gokula Kumar ${ }^{1}$, Tengku Sifzizul Tengku Muhammad ${ }^{2,3}$, \\ Imran Abdul Khalid ${ }^{4}$ and Mei Lan Tan ${ }^{*}, 1,3$ \\ ${ }^{I}$ Advanced Medical and Dental Institute, Universiti Sains Malaysia, Pulau Pinang, Malaysia \\ ${ }^{2}$ Faculty of Science and Technology, Universiti Malaysia Terengganu, 21030 Kuala Terengganu, Terengganu, Malaysia \\ ${ }^{3}$ Malaysian Institute of Pharmaceuticals and Nutraceuticals, Ministry of Science, Technology and Innovation, \\ SAINS@USM, Persiaran Bukit Jambul, 11900 Pulau Pinang, Malaysia \\ ${ }^{4}$ Surgical Unit, Hospital Seberang Jaya, Pulau Pinang, Malaysia
}

\begin{abstract}
Autophagy is a protein degradation process within the cell and its deregulation has been linked to various diseases and the formation of cancer. Both mTOR and Beclin-1 are important proteins involved in the regulation of autophagy process and tumorigenesis. The aims of the study were to assess the expression of autophagic-related proteins in breast cancer tissues and normal breast tissues adjacent to the tumor. Immunohistochemical staining with anti-mTOR, anti-p-mTOR and anti-Beclin-1 antibody was carried out on tissue samples of 24 patients from our local hospitals. The results showed that mTOR and Beclin-1 proteins were present in both types of tissues in all the cases. However, a significant majority of the adjacent normal breast tissues were found to have stronger immunoreactivity towards phosphorylated mTOR (p-mTOR) as compared to the corresponding tumor tissues. Since increased expression of pmTOR is known to be correlated with tumorigenesis, this may indicate the presence of molecular changes in these cells adjacent to the tumor tissues. Patients with mTOR positive tumors may benefit from use of mTOR inhibitors as part of their pharmacotherapy management.
\end{abstract}

Keywords: mTOR, p-mTOR, Beclin-1, breast cancer, immunohistochemistry.

\section{INTRODUCTION}

Autophagy is a complex process involving dynamic rearrangements of membranes to deliver proteins and organelles from the cytoplasm to the vacuoles. It is a highly conserved degradation process and is responsible for the turnover of dysfunctional organelles and proteins $[1,2]$. The process is crucial to maintain a well-controlled balance between anabolism and catabolism to facilitate normal cell growth and development. Autophagy is known to play essential role during starvation, cellular differentiation, cell death, cell survival, aging and tumor prevention [2-6]. In general, autophagy promotes survival to stress but there are evidences that if the process is over-stimulated, it can progress to cell death, which is often referred to as autophagic cell death [7]. Since autophagy is known to be regulated by several tumor suppressor proteins such as Beclin-1 and PTEN, it has been hypothesized that a decrease in autophagy may be associated with tumor progression [5, $8,9]$. Furthermore, stimulation of autophagy in cancer cells was observed in response to anti-cancer treatments as well as

*Address correspondence to this author at the Advanced Medical and Dental Institute, Universiti Sains Malaysia, Pulau Pinang, Malaysia and Malaysian Institute of Pharmaceuticals and Nutraceuticals, Ministry of Science, Technology and Innovation, SAINS@USM, Persiaran Bukit Jambul, 11900 Pulau Pinang, Malaysia; Tel: +604-6535628; Fax: +604-6535604;

E-mails: tanml@usm.my,drtanmelan@yahoo.com herbs, which indicates the potential utility of autophagic cell death induction in cancer therapy [4, 10-14]. The autophagy process is known to be regulated by both mTOR kinase and Beclin-1 tumor suppressor protein [15-24].

The mammalian target of rapamycin, commonly known as mTOR, is a serine/threonine kinase which belongs to the family of phosphatidylinositol kinase-related kinase. It regulates translation and cell growth by its ability to phosphorylate both 4E-BP1 and p70s6k. Phosphoinositide 3 kinase (PI3K) and Akt activation by growth factors leads to the activation of mTOR and subsequently phosphorylation of these substrates. Phosphorylation of p70s6k promotes ribosome biogenesis and increases the capacity of the translational machinery for protein synthesis [25]. Phosphorylation of 4E-BP1 initiates the transcription of a subset of mRNAs important for cell growth and proliferation [25-28]. The mTOR kinase is also a key regulatory component that controls the induction of autophagy [14, 29, 30]. Inhibition of mTOR (by nutrient-depletion, starvation or rapamycin) leads to cell cycle arrest, inhibition of cell proliferation, immunosuppression and induction of autophagy. Increased levels of the mTOR kinase is found to inhibit the autophagy process, resulting in an increased in cell growth and tumor development [14]. Rapamycin, which inhibits the mTOR signaling pathways, induces autophagy and inhibits the proliferation of a variety of cells [31]. 
Beclin-1 is a $60 \mathrm{KDa}$ tumor suppressor protein and is identified from a yeast two-hybrid screen as interacting with Bcl-2 [32]. Beclin-1 is found to be mono-allelically deleted in a high percentage of ovarian, breast and prostate cancers (based on the 17q21 and gene mapping studies). Reduced expression of Beclin-1 is associated with a reduced autophagic vacuole formation [33, 34]. Overexpression of Beclin-1 in MCF-7 human breast cancer cells is found to facilitate autophagy induced by serum and amino-acid deprivation, which indicates that Beclin-1 is a necessary regulator for autophagy [8]. Beclin-1 is known to bind to Class III P13K, which promotes the trafficking of lysosomal enzymes to the lysosomes, is an important step in the formation of autophagosomes [14]. Down-regulation of Beclin-1 expression has been implicated in carcinogenesis [35].

Currently, the link between mTOR and beclin-1 is still unclear [36]. The role of these proteins and autophagy in tumorigenesis remain unclear as most observations and deductions were based on in vitro experiments. Therefore, it will be interesting to know the expression patterns of these autophagy-related proteins in human tumors. Beclin-1 and mTOR proteins may be potential diagnostic or prognostic markers in breast cancers. Thus, the main aim of the study was to evaluate the expression of mTOR, p-mTOR and Beclin-1 protein in breast cancer tissues and the corresponding normal tissues adjacent to the tumors.

\section{MATERIALS AND METHODOLOGY}

\section{Tissue Samples}

The present study was carried out on formalin-fixed paraffin-embedded tissue samples. Breast cancer tissues and corresponding adjacent non-cancerous tissues were obtained from 24 breast cancer patients who had undergone tumor resection at Seberang Jaya Hospital and Kepala Batas Hospital, Pulau Pinang, Malaysia. The tissue samples were obtained from 17 patients with invasive ductal carcinoma, 2 patients with medullary carcinoma, 2 patients with ductal carcinoma in situ (DCIS), 2 patients with invasive combined ductal and lobular carcinoma and 1 patient with signet-ring carcinoma. Data on patient's age, tumor receptor status (ER, PR and C-erb), clinical stage and tumor grade was obtained from the hospital records. This study was approved by the School of Medical Sciences, Universiti Sains Malaysia Ethical Committee Board and informed consent was obtained from each patient before the acquisition of these tissues. The haematoxylin and eosin-stained slides were reviewed by one independent pathologist. Histological grading of the breast cancer was based on the Modified Bloom-Richardson Grading Scheme.

\section{Reagents and Antibodies}

Rabbit monoclonal anti-mTOR and anti-p-mTOR (Ser2448) antibody was purchased from Abcam, Inc., (UK) and Cell Signaling Technology, Inc., (USA), respectively. Rabbit polyclonal anti-Beclin-1 was obtained from Santa Cruz Biotechnology, Inc., (USA). Rabbit IgG was purchased from Sigma-Aldrich, Inc., (USA). Dako REAL ${ }^{\mathrm{TM}}$ EnVision $^{\mathrm{TM}}$ Detection Kit (Peroxidase/DAB rabbit/mouse), target retrieval solution and antibody diluent were purchased from Dako Cytomation (Denmark). As negative control, rabbit
IgG (Sigma Aldrich, USA) was used instead of primary antibody. Human breast cancer slides known to express mTOR, p-mTOR or Beclin-1 were used as positive controls in all experiments.

\section{Immunohistochemistry Detection in Tissues}

Deparaffinization of the tissue sections $(3 \mu \mathrm{m})$ was carried out by heat treatment at $60^{\circ} \mathrm{C}$ for $30 \mathrm{~min}$. This was followed by rehydration of the slides through a series of graded alcohol to water. Endogenous peroxidase activity was blocked by incubating the sections in two changes of $3 \%$ $(\mathrm{v} / \mathrm{v}) \mathrm{H}_{2} \mathrm{O}_{2}$ in phosphate buffered saline (PBS) $(\mathrm{pH} 7.4)$ at room temperature. Antigen retrieval using Target Retrieval Solution, pH 9.0 (Dako, Denmark) was performed according to manufacturer's procedures. Immunohistochemistry procedures and antibody titration was carried out using Dako REAL $^{\mathrm{TM}}$ EnVision $^{\mathrm{TM}}$ Detection System, (Dako, Denmark). Briefly, the slides were rinsed with PBS for $5 \mathrm{~min}$, and nonspecific antibody binding was blocked by incubation of the tissue slides with horse serum before proceeding to the primary antibodies. Immunostaining was visualized using DAB chromogen (Dako, Denmark). Positive staining to the proteins was recognized under light microscope as a diffuse cytoplasmic brown color stain. Sections were counterstained with Mayer's haematoxylin solution. Replacement of the primary antibody with rabbit $\operatorname{IgG}$ was used as negative control in each batch of experiment and was run in parallel.

\section{Assessments of mTOR, p-mTOR and Beclin-1 Immunostaining and Statistical Analysis}

Assessments of the immunostaining were carried out by a pathologist and a researcher, trained in immunohistochemistry methods. A consensus opinion was arrived on the intensity of staining and percentage of cells stained. The percentage of positively stained cells was also determined by counting a minimum of 100 cells, and the average counts were recorded. The staining intensity was graded as absent (-) or present either as weak $(+)$, moderate $(++)$ or strong $(+++)$. The optimized dilution for the primary antibodies was determined at 1:50 for mTOR and p-mTOR and 1:100 for Beclin-1. Pearson Chi Square Test was used to examine the association between categorical characteristics. Nonparametric Wilcoxon Signed Rank Test was used to determine the differences in the expression levels (based on semi-quantitative scores; $+=1,++=2,+++=3$ ) of mTOR, p-mTOR and Beclin-1 in tumor and corresponding normal tissues, respectively. P-values of less than 0.05 were considered significant. Statistical analysis was performed using SPSS version 15.0 for Windows (SPSS Inc., USA).

\section{RESULTS}

In this study, mTOR and Beclin-1 protein expression was successfully evaluated using immunohistochemistry method in a total of 24 cases of breast cancer tissues and corresponding normal tissues adjacent to the tumors. However, as for p-mTOR protein, only 20 of 24 cases were evaluated (missing data for 4 cases). The immunohistochemical results for mTOR, p-mTOR and Beclin-1 expression and clinicopathological parameters are summarized in Table $\mathbf{1}$.

All three proteins, namely, mTOR, p-mTOR, and Beclin1 were observed in the cytoplasm of tissues that were stained 
Table 1. Clinicopathological Data and Autophagy-Related Proteins Expression in Breast Cancer and Corresponding Adjacent Normal Breast Tissues

\begin{tabular}{|c|c|c|c|c|c|c|c|c|c|c|c|c|c|c|}
\hline $\begin{array}{c}\text { Case } \\
\text { Number }\end{array}$ & Sex & Age & Diagnosis & Grade & Stage & ER & PR & C-erb & \multicolumn{2}{|c|}{ mTOR } & \multicolumn{2}{|c|}{ p-mTOR } & \multicolumn{2}{|c|}{ Beclin-1 } \\
\hline 2 & $\mathrm{~F}$ & 41 & IDC & III & IV & + & + & +++ & ++ & ++ & + & +++ & +++ & +++ \\
\hline 3 & $\mathrm{~F}$ & 45 & IDC & I & III & + & - & +++ & +++ & +++ & ++ & +++ & +++ & +++ \\
\hline 5 & $\mathrm{~F}$ & 50 & $\mathrm{MC}$ & III & II & ND & ND & ND & +++ & ++ & + & +++ & ++ & ++ \\
\hline 6 & M & 43 & IDC & III & II & + & - & +++ & +++ & +++ & ++ & +++ & +++ & +++ \\
\hline 7 & $\mathrm{~F}$ & 34 & IDC & III & III & ND & ND & ND & +++ & +++ & + & +++ & ++ & +++ \\
\hline 8 & $\mathrm{~F}$ & 62 & DCIS & ND & 0 & - & - & +++ & +++ & +++ & ++ & +++ & +++ & ++ \\
\hline 12 & $\mathrm{~F}$ & 74 & $\mathrm{MC}$ & III & II & - & - & + & +++ & +++ & + & +++ & +++ & +++ \\
\hline 13 & $\mathrm{~F}$ & 62 & IDC & III & III & ND & ND & ND & +++ & ++ & + & +++ & ++ & ++ \\
\hline 14 & $\mathrm{~F}$ & 44 & IDC & I & II & + & + & +++ & ++ & ++ & ++ & +++ & +++ & +++ \\
\hline 15 & $\mathrm{~F}$ & 33 & DCIS & ND & II & - & - & ND & +++ & +++ & ++ & +++ & +++ & +++ \\
\hline 16 & $\mathrm{~F}$ & 47 & IDC & I & III & + & + & + & +++ & +++ & ++ & +++ & ++ & +++ \\
\hline 17 & $\mathrm{~F}$ & 59 & IDC & III & III & - & - & +++ & +++ & +++ & + & +++ & +++ & +++ \\
\hline 18 & $\mathrm{~F}$ & 48 & IDC & II & III & - & - & + & +++ & +++ & - & +++ & ++ & +++ \\
\hline
\end{tabular}

+, weak stained; ++, moderate stained; +++, strong stained; -, negative stain; ND, undetermined; IDC,invasive ductal carcinoma; DCIS, ductal carcinoma in situ; MC. Medullary carcinoma; SRC, signet-ring carcinoma; ICDLC, invasive combined ductal and lobular carcinoma.

The clinical data presented in the table were obtained from patients'record (Hospital Seberang Jaya and Hospital Kepala Batas, Pulau Pinang, Malaysia).

positive. The percentage of cells stained positive for all three proteins were found to be more than $90 \%$ in all tissues. Negative control slides produce absent staining for all three proteins in all experiments. A co-expression of all three proteins (mTOR, p-mTOR and Beclin-1) was found in 18 $(75 \%)$ cases of both tumor and normal tissues. mTOR and Beclin-1 staining was positive in all 24 carcinomas and corresponding non-tumor tissues. Of the entire breast tumor tissues analyzed, 21 of $24(87.5 \%)$ cases exhibited strong mTOR expression while the rest showed moderate expression. In comparison with the adjacent non-tumor tissues, only 17 of $24(70.8 \%)$ and 7 of $24(29.1 \%)$ of the cases exhibited strong and moderate staining intensity respectively. However, only 5 of $24(20.8 \%)$ of the tumors expressed the mTOR protein strongly $(3+)$ as compared to the corresponding normal tissues $(2+)$. There were no significant differences in mTOR staining pattern between normal and tumor tissues.
As for Beclin-1 protein, 16 of $24(66.7 \%)$ of the tumor tissues expressed the protein strongly while the rest ( 8 of 24, $33.3 \%$ ) were of moderate expression. By contrast, more normal tissues $(18 / 24,75 \%)$ expressed the protein strongly, $5 / 24(20.8 \%)$ moderately, while a single case showed a weak expression. However, only 5 of $24(20.8 \%)$ cases exhibited stronger $(3+)$ Beclin-1 expression as compared to their corresponding normal tissues $(2+)$. There were no observed differences in the Beclin-1 staining pattern between normal and tumor tissues.

mTOR and Beclin-1 protein were found to be expressed in both tumor and adjacent normal tissues. Interestingly, only $1 / 20$ of the tumor tissues showed a strong p-mTOR expression while 9 of $20(45 \%)$ and 8 of $20(40 \%)$ of the cases exhibited moderate and weak expression, respectively. Two tumor tissues (IDC, SRC) were tested negative for this protein but its adjacent normal tissues were found to express the protein strongly. Unexpectedly, all 20/20 adjacent 
normal tissues expressed p-mTOR protein strongly in comparison with the tumor tissues which showed only weak to moderate in staining. There was a statistical difference in $\mathrm{p}$-mTOR expression between tumor and normal tissues $(\mathrm{p}<$ 0.05 ). A higher number of adjacent normal tissues appeared to express the phosphorylated form of mTOR more strongly than the corresponding tumor tissues.

No significant association was found between mTOR, pmTOR and Beclin-1 protein expression and patients' clinicopathological parameters, such as age group, tumor grade, clinical stage and receptor status. Representative images from tissue samples expressing proteins of different staining intensity are shown in Fig. (1) (mTOR) and Fig. (2) (p-mTOR) and Fig. (3) (Beclin-1), respectively.

\section{DISCUSSION}

Breast cancer is a very heterogeneous tumor and the pathogenesis of this cancer is multi-factorial. However, studying molecular changes may help in the identification of certain subgroups with specific behavior, which will further contribute to a better understanding of tumor progression and subsequently individualized pharmacotherapy. The mammalian target of rapamycin (mTOR) is a protein kinase that is centrally involved in the control of cancer cell metabolism, growth, proliferation and autophagy. The mTOR pathway has attracted broad scientific and clinical interest, particularly in light of the ongoing clinical cancer trials with mTOR inhibitors. Deregulated signaling of mTOR, Beclin-1 and aberrant autophagy process has been linked to tumor progression [37, 38].

Immunohistochemistry method was used to detect the expression of mTOR, p-mTOR and Beclin-1 proteins in both tumor and adjacent normal breast tissues of our Malaysian patients. The preliminary results showed that both tumor and adjacent normal tissues (100\%) expressed the mTOR and Beclin-1 protein, producing weak to high staining intensity. There were no observed differences in the expression pattern between the two groups of tissues as both tumor and adjacent normal tissues appeared to express the protein similarly. By contrast, a vast majority of the normal tissues were found to express the activated form of mTOR (p-mTOR) protein at a higher staining intensity as compared to their corresponding tumor tissues, even though the expression of mTOR in both types of tissues was of moderate to strong. The relatively higher expression of p-mTOR in these normal tissues may suggest the presence or onset of molecular changes.

Our preliminary results were different from other published studies. Zhou and co-workers examined 165 breast cancers with specific antibody for phosphorylated mTOR using immunohistochemistry, cell culture and western blot techniques [39]. They found that the expression of p-mTOR protein was increased from normal breast epithelium to hyperplasia and abnormal hyperplasia to tumor invasion. Higher levels of p-mTOR were associated with poor diseasefree survival. The overall results supported the trend that phosphorylation of mTOR increases with the progression of tumor. Another study, Lin and co-workers examined mTOR phosphorylation status in tissue microarray slides containing 89 invasive breast cancer tissues as well as six normal mammary tissues by using immunohistochemistry staining.
(A)

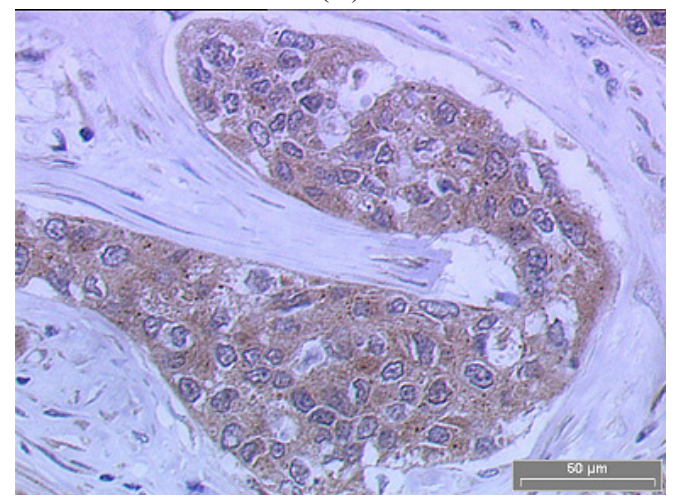

(B)

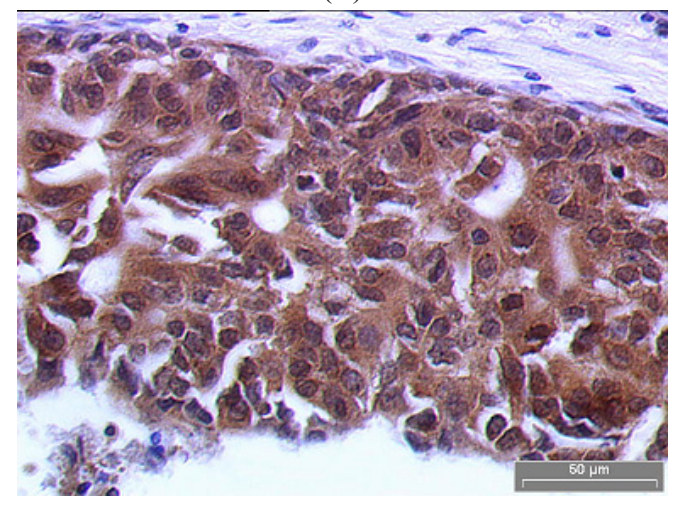

(C)

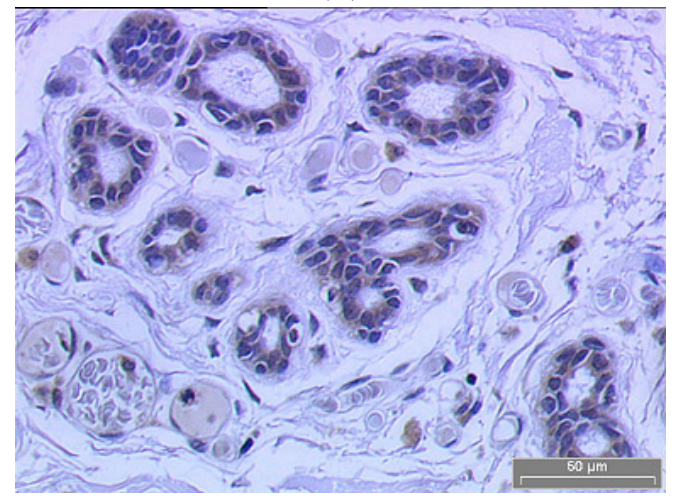

(D)

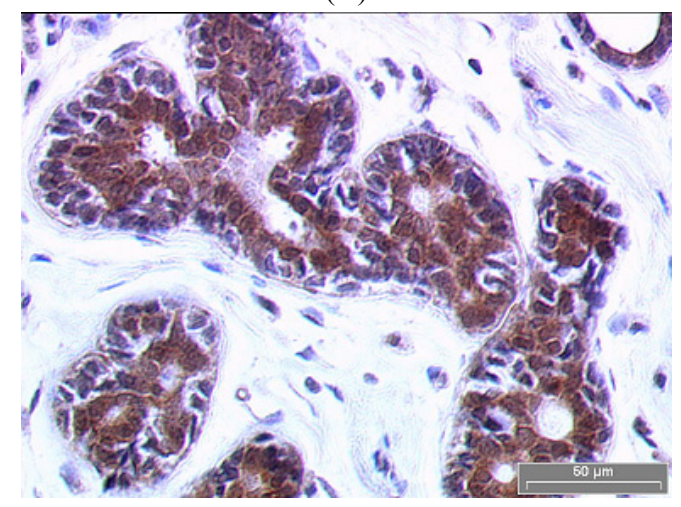

Fig. (1). Representative immunohistochemical staining of mTOR protein in breast cancer tissues and corresponding adjacent normal breast tissues. (A, B), moderate and strong expression for mTOR in breast cancer tissues; (C, D), moderate and strong expression for mTOR in adjacent normal breast tissues; None of the tissues produced weak staining (200 x magnification). 
(A)

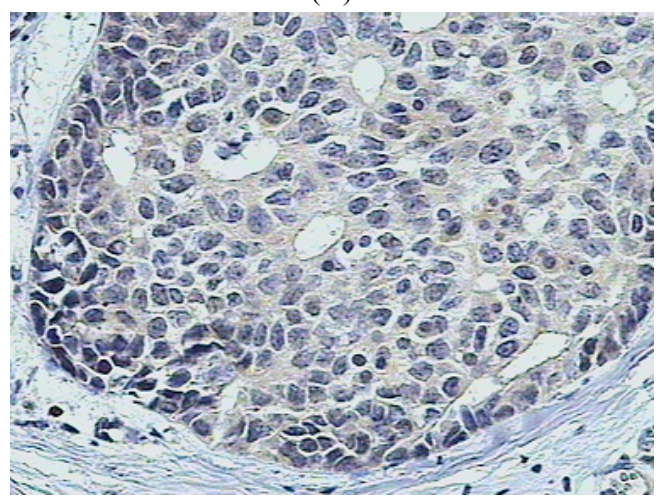

(B)

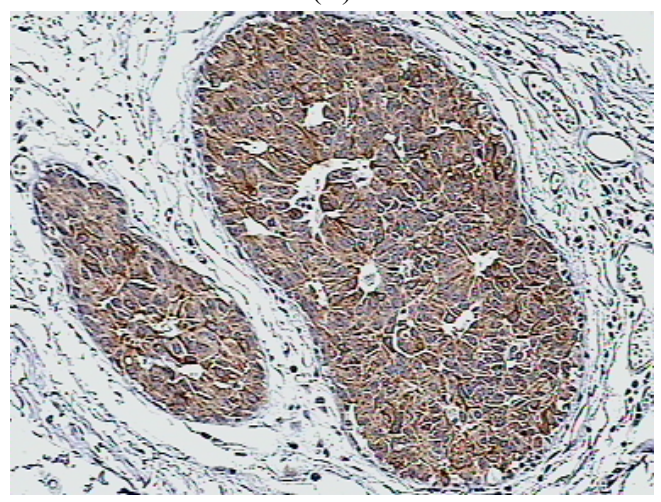

(C)

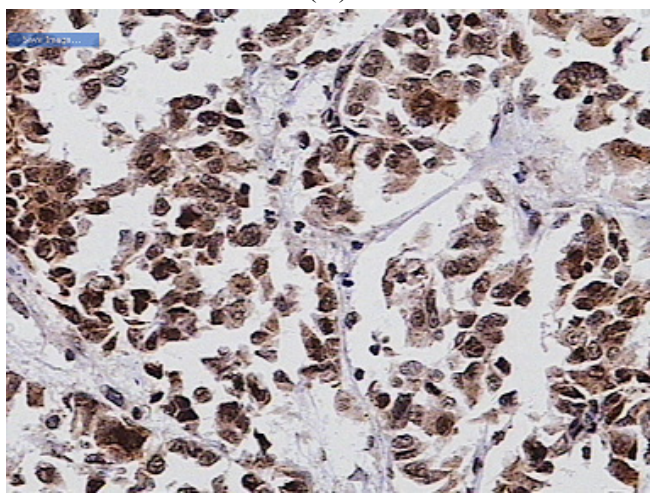

(D)

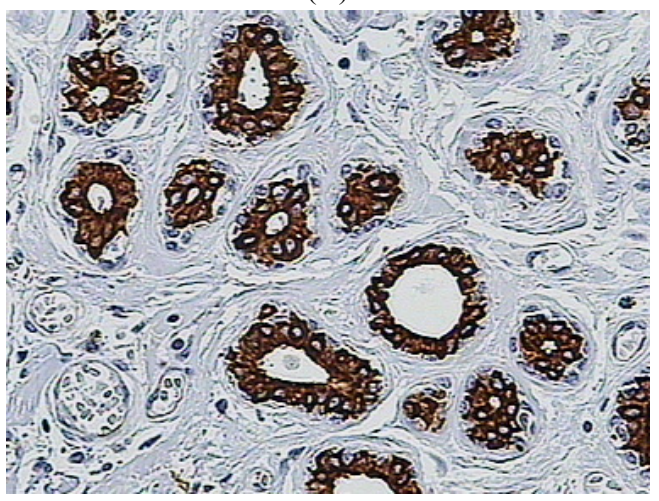

Fig. (2). Representative immunohistochemical staining of p-mTOR protein in breast cancer tissues and corresponding adjacent normal breast tissues. (A, B, C), weak, moderate and strong expression for p-mTOR in breast cancer tissues; (D) strong expression for mTOR in adjacent normal breast tissues. None of the normal tissues produced weak or moderate staining (200 x magnification).
(A)

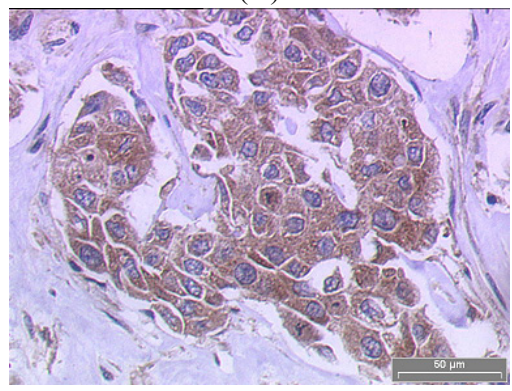

(B)

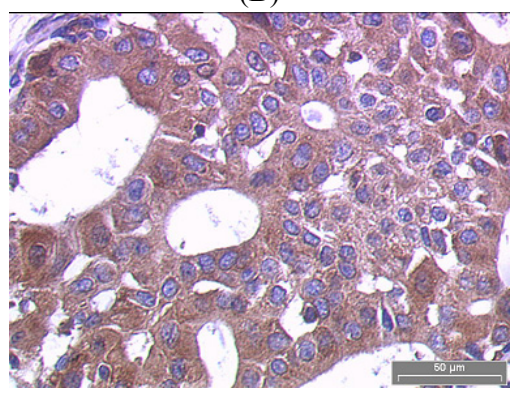

(C)

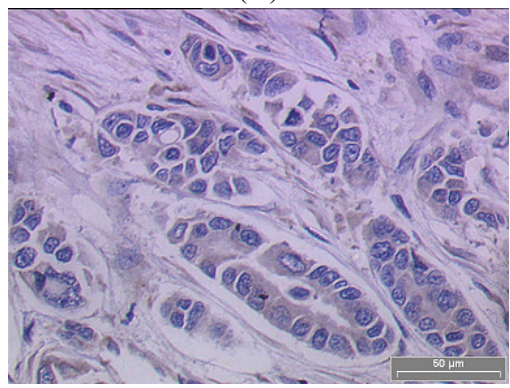

(D)

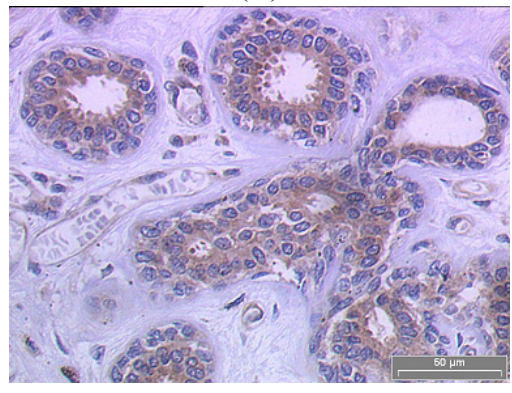

(E)

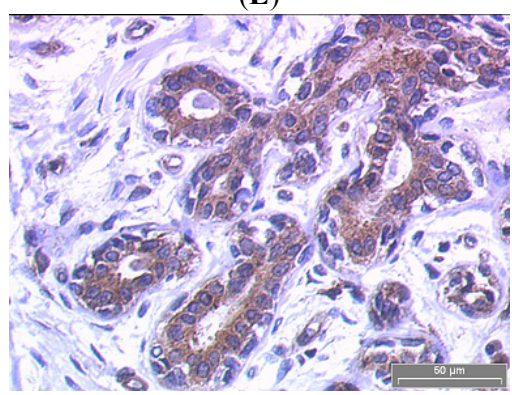

Fig. (3). Representative immunohistochemical staining of Beclin-1 protein in breast cancer tissues and corresponding adjacent normal breast tissues. (A) and (B), moderate and strong expression for Beclin-1 in breast cancer tissues; $(\mathbf{C}, \mathbf{D}, \mathbf{E})$ weak, moderate and strong expression for Beclin-1 in adjacent normal breast tissues. None of the tumor tissues produced weak staining $(200 \mathrm{x}$ magnification). 
Elevated phosphorylation of mTOR was highly associated with invasive breast tumors [40]. In both studies above, the sources of the normal tissues were not obtained directly from the corresponding tissues adjacent to the tumor tissues. In short, the samples used in this study are paired whereas the ones used by the above studies were not. Furthermore, the limitation of sample size could have also contributed to the differences in results.

As for the Beclin-1 protein, both tumor and adjacent normal tissues expressed the protein similarly, producing weak to high intensity staining. Since all samples expressed the protein, there was no observed association between the expression of this protein and patient's clinicopathological parameters. The results in this study were also different from some published data. Beclin-1 was found to be monoallelically deleted in $40-75 \%$ of human breast cancers [8]. Its expression was found to be low in human breast epithelial carcinoma cell lines and tissues, as compared to normal breast epithelia [8]. Another study which examined the expression of Beclin-1 in 11 gastric cancers and adjacent non-cancerous gastric mucosa using RT-PCR and western blot showed that the mRNA and protein expression of Beclin-1 was lower in cancer tissues as compared to noncancerous tissues [41]. These findings suggested that a decrease in the expression of autophagy proteins such as Beclin-1 may contribute to the progression of breast and other human cancers. However, Beclin-1 was found to be expressed in all the 24 tumors analyzed in this local study. This results actually concurred with a recent finding that mentioned that the expression of beclin-1 was detected in $95 \%$ of colorectal carcinomas and $83 \%$ of gastric carcinomas examined. The authors even further suggested that beclin-1 inactivation by loss of expression may not occur in colorectal and gastric carcinomas [42]. Therefore, it is not surprising that Beclin-1 expression is present in these breast cancer tissues.

There may be several possible reasons why more normal breast tissues were found to express the activated form of mTOR (p-mTOR) protein at a higher staining intensity as compared to their corresponding tumor tissues, even though the expression of mTOR in both types of tissues was of moderate to strong in intensity. This may suggest the presence or onset of molecular changes in these tissues adjacent to the tumors. Therefore, these tissues may not be entirely normal, despite morphologically defined as normal. Many studies have examined possible genetic alterations adjacent to precancerous and cancerous lesions [43, 44]. Lydiatt and co-workers have found that there was clonality relationship between dysplasias and normal tissue adjacent to tumor in approximately half of the tested cancers [45]. Other studies have demonstrated a $43 \%$ concordance between tumors and adjacent pre-malignant tissues by using microsatellite analysis [46]. Another interesting study examined the reliability of histological diagnosis of clinically normal intra-oral tissue adjacent to clinically suspicious lesions in the upper aerodigestive tract of cancer patients [47]. According to the study, the authors noted that histological diagnosis of clinically normal oral specimens adjacent to suspicious tissues has low reliability. All these studies suggested that tissues surrounding the malignancy have already possessed molecular alterations. Therefore, using normal tissues adjacent to the tumor tissues as comparison to cancer tissues in experiments may produce aberrant results.

In conclusion, Beclin-1 and mTOR protein is present in all breast tumor tissues as well as the corresponding normal tissues used in this study. There was no observed relationship between the expression of mTOR, p-mTOR, Beclin-1 and clinicopathological parameters. Majority of the adjacent normal tissues have exhibited stronger expression of $\mathrm{p}$-mTOR protein compared to the corresponding tumor tissues. Since p-mTOR activity is linked to the progression of cancer, the presence of an increased activity of p-mTOR in these normal tissues may be a conditioning factor for the cells to undergo morphological changes. However, this would need further verification. The strong expression of mTOR in the tumor and surrounding tissues coupled with the strong expression of Beclin-1 gave no information which may link these two proteins to breast cancer development. Patients with mTOR positive tumors may benefit from use of mTOR inhibitors as part of their pharmacotherapy management

\section{ACKNOWLEDGEMENTS}

This work was supported by the Sciencefund, Ministry of Science, Technology and Innovation Malaysia. The authors are also thankful to the staffs at Pusat Klinikal IPPT for their technical assistance.

\section{ABBREVIATIONS}

$\begin{aligned} \mathrm{mTOR} & =\text { Mammalian target of rapamycin } \\ \mathrm{p}-\mathrm{mTOR}= & \begin{array}{l}\text { Phosphorylated-mammalian target of } \\ \text { rapamycin }\end{array}\end{aligned}$

\section{REFERENCES}

[1] Ferraro E, Cecconi F. Autophagic and apoptotic response to stress signals in mammalian cells. Arch Biochem Biophys 2007; 462(2): 210-9.

[2] Levine B, Klionsky DJ. Development by self-digestion: molecular mechanisms and biological functions of autophagy. Dev Cell 2004; 6(4): 463-77.

[3] Klionsky DJ. Autophagy: from phenomenology to molecular understanding in less than a decade. Nat Rev Mol Cell Biol 2007; 8(11): 931-7.

[4] Tan ML, Muhammad TS, Najimudin N, Sulaiman SF. Growth arrest and non-apoptotic programmed cell death associated with the up-regulation of c-myc mRNA expression in T-47D breast tumor cells following exposure to Epipremnum pinnatum (L.) Engl. hexane extract. J Ethnopharmacol 2005; 96(3): 375-83.

[5] Meijer AJ, Codogno P. Regulation and role of autophagy in mammalian cells. Int J Biochem Cell Biol 2004; 36(12): 2445-62.

[6] Reggiori F, Klionsky DJ. Autophagy in the eukaryotic cell. Eukaryot Cell 2002; 1(1): 11-21.

[7] White E. Autophagic cell death unraveled: Pharmacological inhibition of apoptosis and autophagy enables necrosis. Autophagy 2008; 4(4): 399-401

[8] Liang XH, Jackson S, Seaman M, et al. Induction of autophagy and inhibition of tumorigenesis by beclin 1. Nature 1999; 402(6762): 672-6.

[9] Shintani T, Klionsky DJ. Autophagy in health and disease: A double-edged sword. Science 2004; 306(5698): 990-5.

[10] Gozuacik D, Kimchi A. Autophagy as a cell death and tumor suppressor mechanism. Oncogene 2004; 23(16): 2891-906.

[11] Bursch W, Hochegger K, Torok L, Marian B, Ellinger A, Hermann RS. Autophagic and apoptotic types of programmed cell death exhibit different fates of cytoskeletal filaments. J Cell Sci 2000; 113 ( Pt 7): 1189-98.

[12] Inbal B, Bialik S, Sabanay I, Shani G, Kimchi A. DAP kinase and DRP-1 mediate membrane blebbing and the formation of 
autophagic vesicles during programmed cell death. J Cell Biol 2002; 157(3): 455-68.

[13] Paglin S, Hollister T, Delohery T, et al. A novel response of cancer cells to radiation involves autophagy and formation of acidic vesicles. Cancer Res 2001; 61(2): 439-44.

[14] Kondo Y, Kanzawa T, Sawaya R, Kondo S. The role of autophagy in cancer development and response to therapy. Nat Rev Cancer 2005; 5(9): 726-34.

[15] Cao C, Subhawong T, Albert JM, et al. Inhibition of mammalian target of rapamycin or apoptotic pathway induces autophagy and radiosensitizes PTEN null prostate cancer cells. Cancer Res 2006; 66(20): 10040-7.

[16] Corradetti MN, Guan KL. Upstream of the mammalian target of rapamycin: Do all roads pass through mTOR? Oncogene 2006; 25(48): 6347-60.

[17] Hashimoto I, Koizumi K, Tatematsu M, et al. Blocking on the CXCR4/mTOR signalling pathway induces the anti-metastatic properties and autophagic cell death in peritoneal disseminated gastric cancer cells. Eur J Cancer 2008; 44(7): 1022-9.

[18] Iwamaru A, Kondo Y, Iwado E, et al. Silencing mammalian target of rapamycin signaling by small interfering RNA enhances rapamycin-induced autophagy in malignant glioma cells. Oncogene 2007; 26(13): 1840-51.

[19] Sarkar S, Ravikumar B, Floto RA, Rubinsztein DC. Rapamycin and mTOR-independent autophagy inducers ameliorate toxicity of polyglutamine-expanded huntingtin and related proteinopathies. Cell Death Differ 2009; 16(1): 46-56.

[20] Miracco C, Cosci E, Oliveri G, et al. Protein and mRNA expression of autophagy gene Beclin 1 in human brain tumours. Int J Oncol 2007; 30(2): 429-36.

[21] Cao Y, Klionsky DJ. Physiological functions of Atg6/Beclin 1: A unique autophagy-related protein. Cell Res 2007; 17(10): 839-49.

[22] Liang C, Feng P, Ku B, et al. Autophagic and tumour suppressor activity of a novel Beclin1-binding protein UVRAG. Nat Cell Biol 2006; 8(7): 688-99.

[23] Liang XH, Yu J, Brown K, Levine B. Beclin 1 contains a leucinerich nuclear export signal that is required for its autophagy and tumor suppressor function. Cancer Res 2001; 61(8): 3443-9.

[24] Pattingre S, Tassa A, Qu X, et al. Bcl-2 antiapoptotic proteins inhibit Beclin 1-dependent autophagy. Cell 2005; 122(6): 927-39.

[25] Jacinto E, Hall MN. Tor signalling in bugs, brain and brawn. Nat Rev Mol Cell Biol 2003; 4(2): 117-26.

[26] Martin KA, Blenis J. Coordinate regulation of translation by the PI 3-kinase and mTOR pathways. Adv Cancer Res 2002; 86: 1-39.

[27] Wang CW, Klionsky DJ. The molecular mechanism of autophagy. Mol Med 2003; 9(3-4): 65-76.

[28] Wang L, Fraley CD, Faridi J, Kornberg A, Roth RA. Inorganic polyphosphate stimulates mammalian TOR, a kinase involved in the proliferation of mammary cancer cells. Proc Natl Acad Sci USA 2003; 100(20): 11249-54.

[29] Boulay A, Lane HA. The mammalian target of rapamycin kinase and tumor growth inhibition. Recent Results Cancer Res 2007; 172: 99-124.

[30] Murakami M, Ichisaka T, Maeda M, et al. mTOR is essential for growth and proliferation in early mouse embryos and embryonic stem cells. Mol Cell Biol 2004; 24(15): 6710-8.
[31] Takeuchi H, Kondo Y, Fujiwara K, et al. Synergistic augmentation of rapamycin-induced autophagy in malignant glioma cells by phosphatidylinositol 3-kinase/protein kinase B inhibitors. Cancer Res 2005; 65(8): 3336-46.

[32] Liang XH, Kleeman LK, Jiang HH, et al. Protection against fatal Sindbis virus encephalitis by beclin, a novel Bcl-2-interacting protein. J Virol 1998; 72(11): 8586-96.

[33] $\mathrm{Qu} \mathrm{X}, \mathrm{Yu}$ J, Bhagat G, et al. Promotion of tumorigenesis by heterozygous disruption of the beclin 1 autophagy gene. J Clin Invest 2003; 112(12): 1809-20.

[34] Yue Z, Jin S, Yang C, Levine AJ, Heintz N. Beclin 1, an autophagy gene essential for early embryonic development, is a haploinsufficient tumor suppressor. Proc Natl Acad Sci USA 2003; 100(25): 15077-82.

[35] Furuya N, Yu J, Byfield M, Pattingre S, Levine B. The evolutionarily conserved domain of Beclin 1 is required for Vps34 binding, autophagy and tumor suppressor function. Autophagy 2005; 1(1): 46-52.

[36] Inoki K, Corradetti MN, Guan KL. Dysregulation of the TSCmTOR pathway in human disease. Nat Genet 2005; 37(1): 19-24.

[37] Bialik S, Kimchi A. Autophagy and tumor suppression: Recent advances in understanding the link between autophagic cell death pathways and tumor development. Adv Exp Med Biol 2008; 615: $177-200$

[38] Chiang GG, Abraham RT. Targeting the mTOR signaling network in cancer. Trends Mol Med 2007; 13(10): 433-42.

[39] Zhou X, Tan M, Stone HV, et al. Activation of the Akt/mammalian target of rapamycin/4E-BP1 pathway by ErbB2 overexpression predicts tumor progression in breast cancers. Clin Cancer Res 2004; 10(20): 6779-88.

[40] Lin HJ, Hsieh FC, Song H, Lin J. Elevated phosphorylation and activation of $\mathrm{PDK}-1 / \mathrm{AKT}$ pathway in human breast cancer. $\mathrm{Br}$ Cancer 2005; 93(12): 1372-81

[41] Furuya D, Tsuji N, Yagihashi A, Watanabe N. Beclin 1 augmented cis-diamminedichloroplatinum induced apoptosis via enhancing caspase-9 activity. Exp Cell Res 2005; 307(1): 26-40.

[42] Ahn CH, Jeong EG, Lee JW, et al. Expression of beclin-1, an autophagy-related protein, in gastric and colorectal cancers. APMIS 2007; 115(12): 1344-9.

[43] Epstein JB, Zhang L, Poh C, Nakamura H, Berean K, Rosin M. Increased allelic loss in toluidine blue-positive oral premalignant lesions. Oral Surg Oral Med Oral Pathol Oral Radiol Endod 2003; 95(1): 45-50.

[44] Ha PK, Califano JA. The molecular biology of mucosal field cancerization of the head and neck. Crit Rev Oral Biol Med 2003; 14(5): 363-9.

[45] Lydiatt WM, Anderson PE, Bazzana T, et al. Molecular support for field cancerization in the head and neck. Cancer 1998; 82(7): 137680 .

[46] Jang SJ, Chiba I, Hirai A, Hong WK, Mao L. Multiple ora squamous epithelial lesions: Are they genetically related? Oncogene 2001; 20(18): 2235-42.

[47] Fischer DJ, Epstein JB, Morton TH Jr, Schwartz SM. Reliability of histologic diagnosis of clinically normal intraoral tissue adjacent to clinically suspicious lesions in former upper aerodigestive tract cancer patients. Oral Oncol 2005; 41(5): 489-96.

This is an open access article licensed under the terms of the Creative Commons Attribution Non-Commercial License (http: //creativecommons.org/licenses/by-nc/ $3.0 /$ ) which permits unrestricted, non-commercial use, distribution and reproduction in any medium, provided the work is properly cited. 